\title{
Defective B-cell proliferation and maintenance of long-term memory in patients with chronic granulomatous disease
}

\author{
Nicola Cotugno, MD, ${ }^{a, b *}$ Andrea Finocchi, MD, $\mathrm{PhD}^{\mathrm{a}, \mathrm{b} *}$ Alberto Cagigi, $\mathrm{PhD},{ }^{\mathrm{a}}$ Gigliola Di Matteo, $\mathrm{PhD},{ }^{\mathrm{a}, \mathrm{b}}$ \\ Maria Chiriaco, PhD, ${ }^{a, b}$ Silvia Di Cesare, PhD, ${ }^{a, b}$ Paolo Rossi, MD, PhD, ${ }^{a, b}$ Alessandro Aiuti, MD, PhD, \\ Paolo Palma, MD, PhD, ${ }_{\ddagger} \ddagger$ and lyadh Douagi, $\mathbf{P h D}_{\ddagger}^{\mathbf{d}_{\ddagger}} \quad$ Rome and Milan, Italy, and Stockholm, Sweden
}

Background: Chronic granulomatous disease (CGD) is a primary immune deficiency characterized by a defect in reactive oxygen species production. Although the effect of CGD mainly reflects on the phagocytic compartment, B-cell responses are also impaired in patients with CGD.

Objective: We sought to investigate how defective gp91 ${ }^{\text {phox }}$ expression in patients with CGD and CGD carriers might affect the B-cell compartment and maintenance of long-term memory. Methods: We studied the B-cell compartment of patients with CGD in terms of phenotype and ability to produce reactive oxygen species and proliferate on stimuli differently directed to the B-cell receptor and Toll-like receptor 9. We further studied their capacity to maintain long-term memory by measuring cellular and serologic responses to measles.

Results: We show that the memory B-cell compartment is impaired among patients with CGD, as indicated by reduced total $\left(\mathrm{CD}^{+}{ }^{+} \mathrm{CD27}^{+}\right)$and resting $\left(\mathrm{CD}^{+}{ }^{+} \mathrm{CD27}{ }^{+} \mathrm{CD21}^{+}\right)$ memory $B$ cells in parallel to increased naive $\left(\mathrm{CD}^{+}{ }^{+} \mathrm{CD27}^{-} \mathrm{IgD}^{+}\right)$B-cell frequencies. Data on CGD carriers reveal that such alterations are related to ${\text { gp } 91^{\text {phox }}}^{\text {expression. }}$ Moreover, proliferative capabilities of $B$ cells on selective in vitro stimulation of $\mathrm{B}$-cell receptor or Toll-like receptor 9 pathways were reduced in patients with CGD compared with those seen in age-matched healthy control subjects. Significantly lower measles-specific antibody levels and antibody-secreting

\footnotetext{
From 'the University Department of Pediatrics, Unit of Immune and Infectious Diseases, Children's Hospital Bambino Gesù, Rome; 'b the Department of Systems Medicine, University of Rome "Tor Vergata"; 'TIGET, Scientific Institute San Raffaele, Milan; and ${ }^{d}$ the Center for Hematology and Regenerative Medicine (HERM), Department of Medicine Huddinge, Karolinska Institutet, Stockholm.

*These authors contributed equally to this work.

\$These authors shared last authorship.

Supported by grants obtained from the Bambino Gesù Children's Hospital and the Karolinska Institutet. Also supported by Cell-PID HEALTH F5-2010-261387, EUROCGD project (ERA-NET E-Rare: "European research projects on rare diseases"), Italian Ministry of Health (Progetto Giovani Ricercatori GR-2008-57 to A.F.).

Disclosure of potential conflict of interest: This study was supported by grants obtained from the Bambino Gesù Children's hospital and from the Karolinska Institutet. A. Finocchi's institution has received funding from Progetto Giovani Ricercatori. A. Aiuti's institution has received funding from the European Union. The rest of the authors declare that they have no other relevant conflicts of interest.

Received for publication October 7, 2013; revised July 8, 2014; accepted for publication July 16, 2014.

Corresponding authors: Alessandro Aiuti, MD, PhD, University Department of Pediatrics, Children Hospital Bambino Gesù, Department of Public Health and Cellular Biology, Tor Vergata, Rome, Italy. E-mail: aaiuti@gmail.com. Or: Paolo Palma, $\mathrm{MD}, \mathrm{PhD}$, University Department of Pediatrics, Children Hospital Bambino Gesù, Department of Public Health and Cellular Biology, Tor Vergata, Rome, Italy. E-mail: paolo.palma@opbg.net. Or: Iyadh Douagi, PhD, Center for Hematology and Regenerative Medicine (HERM), Department of Medicine Huddinge, Karolinska Institutet, Stockholm, Sweden. E-mail: iyadh.douagi@ki.se.

0091-6749/\$36.00

(C) 2014 American Academy of Allergy, Asthma \& Immunology

http://dx.doi.org/10.1016/j.jaci.2014.07.012
}

cell numbers were also observed, indicating a poor ability to maintain long-term memory in these patients.

Conclusion: Altogether, our data suggest that patients with CGD present a defective B-cell compartment in terms of frequencies of memory $B$ cells, response to in vitro stimulation, and maintenance of long-term antigen-specific memory. (J Allergy Clin Immunol 2014;

Key words: Chronic granulomatous disease, B cell, proliferation, long-term memory, measles, memory B-cell compartment, reactive oxygen species deficiency

Chronic granulomatous disease (CGD) is a primary immune deficiency caused by defects in the phagocyte nicotinamide adenine dinucleotide phosphate (NADPH) oxidase. The phagocyte oxidase generates superoxide and other reactive oxygen species (ROS) by transferring electrons from NADPH to molecular oxygen and consists of the catalytic subunit gp91 ${ }^{\text {phox }}$, which is structurally stabilized by $\mathrm{p} 22^{\mathrm{phox}}$ protein, and the regulatory subunits $\mathrm{p} 47^{\text {phox }}, \mathrm{p} 40^{\text {phox }}, \mathrm{p} 67^{\text {phox }}$, and Ras-related C3 botulinum toxin substrate (RAC). ${ }^{1,2}$ As a consequence, phagocytes of patients affected by CGD are unable to kill ingested microorganisms, resulting in augmented susceptibility to recurrent life-threatening pyogenic infections. ${ }^{3-6}$

Although CGD is primarily recognized as an oxidative deficiency of the phagocytic compartment, key cellular pathways, including lymphocyte function, were also shown to link to ROS production. Furthermore, patients affected by CGD have been described to present lower frequencies of circulating memory B cells, ${ }^{9,10}$ with an intact humoral immunologic memory. ${ }^{10}$ This was shown primarily in patients receiving immunosuppressive therapies. ${ }^{10}$

Recent mouse studies showed a direct relation between the B-cell stimulation and the production of ROS. Lower activity of the NADPH oxidase could impair B-cell receptor (BCR) signal strength, reducing activation and proliferation of $\mathrm{B}$ cells in response to surface immunoglobulin cross-linking. ${ }^{11-13}$ However, the role of ROS production in sustaining human B-cell function and long-term maintenance of memory B-cell responses remains poorly understood.

Here we performed an extensive phenotypic and functional characterization of $\mathrm{B}$ cells in the peripheral blood of patients with CGD who were not undergoing immunosuppressive therapies. Monitoring of B-cell proliferation on direct triggering of BCR pathways, Toll-like receptor (TLR) 9 pathways, or both revealed a partial impairment of B-cell function in patients with CGD. Subsequent analyses of vaccine-induced antibody responses against measles indicated defective long-term maintenance in terms of both serum antibody levels and numbers of circulating antibodysecreting cells (ASCs). 


\author{
Abbreviations used \\ Anti-Ig: $\mathrm{F}\left(\mathrm{ab}^{\prime}\right)_{2}$ fragment goat anti-human $\operatorname{IgA}+\operatorname{IgG}+\operatorname{IgM}$ \\ ASC: Antibody-secreting cell \\ BCR: B-cell receptor \\ CGD: Chronic granulomatous disease \\ HC: Healthy control subject \\ NADPH: Nicotinamide adenine dinucleotide phosphate \\ PMA: Phorbol 12-myristate 13-acetate \\ PWM: Pokeweed mitogen \\ ROS: Reactive oxygen species \\ TLR: Toll-like receptor
}

\section{METHODS}

\section{Study subjects}

Ten patients with CGD, 13 age-matched healthy control subjects (HCs), and 4 CGD carriers (mothers of 4 of the enrolled patients) were enrolled at the University Department of Pediatrics, Unit of Immune and Infectious Diseases, Children's Hospital Bambino Gesù, Rome, Italy. Participating patients and their family members provided written consent for evaluation and follow-up. All experiments were reviewed and approved by the appropriate institutional review board. Patients were considered to have the X-recessive form of the disease, as previously described. ${ }^{14}$ The CGD group consisted of 9 patients with the X-linked form and 1 with the autosomal recessive form of CGD. Patients' characteristics are listed in Table I. All patients with CGD were clinically stable, and only 1 patient was receiving immunosuppressive therapy (azathioprine) because of a concomitant inflammatory bowel disease. Nonetheless, no evidence for differences in terms of both cellular and humoral immunity was found compared with the other patients with CGD. According to the national routine vaccination protocol, all patients and $\mathrm{HCs}$ received measles vaccination (Priorix; GlaxoSmithKline, Research Triangle Park, NC) between 12 and 15 month of age and at 5 years of age.

\section{Flow cytometric analyses}

PBMCs were obtained by using density gradient centrifugation with Ficoll-Hypaque EDTA (Amersham Pharmacia Biotech, Little Chalfont, United Kingdom). Control samples from healthy volunteers were analyzed concurrently with experimental samples. PBMCs were stained, as previously described. ${ }^{15}$ In all experiments B-cell subsets were identified based on $\mathrm{CD} 19^{+}$ expression. Other antibodies included were CD21, CD27, IgD, CD38, CD10, CD3, CD24, and CD27, all from BD (Franklin Lakes, NJ). All antibodies were previously titrated. Viable lymphocytes were identified with Live/Dead violet stain (Invitrogen, Carlsbad, Calif). Samples were analyzed on an LSRFortessa (BD) with Diva software. Data analysis was performed with FlowJo software (Tree Star, Ashland, Ore).

\section{Proliferation assays}

Total PBMCs were labeled for 7 minutes at $37^{\circ} \mathrm{C}$ with $0.25 \mu \mathrm{mol} / \mathrm{L}$ carboxyfluorescein succinimidyl ester (Invitrogen), according to the manufacturer's protocol. Cells were resuspended at a concentration of $2.5 \times 10^{5}$ cells per well and cultured at $37^{\circ} \mathrm{C}$ in the presence of $2.5 \mu \mathrm{g} / \mathrm{mL} \mathrm{F}\left(\mathrm{ab}^{\prime}\right)_{2}$ Fragment Goat Anti-Human IgA+IgG+IgM (anti-Ig; Jackson ImmunoResearch, West Grove, Pa), $10 \mu \mathrm{g} / \mathrm{mL}$ pokeweed mitogen (PWM; Sigma, St Louis, Mo), and $5 \mu \mathrm{g} / \mathrm{mL}$ CpG-DNA ODN 2006 (CpG; Hycult Biotech, Plymouth Meeting, Pa) mixed in different combinations. After 5 days of culture, cells were resuspended; labeled for CD19 or CD19, CD27, CD10, $\mathrm{IgD}$, and Live/Dead Violet stain; and analyzed by using flow cytometry on an LSRFortessa (BD) with Diva 6.x software. Cells per well $\left(5 \times 10^{4}\right)$ were acquired by using flow cytometry. An average of $68 \%$ recovery was found among the samples, with no significant differences between the different conditions. Data analysis was performed with FlowJo software (Tree Star).

\section{ELISpot assay}

PBMCs were stimulated with $10 \mu \mathrm{g} / \mathrm{mL}$ PWM and $5 \mu \mathrm{g} / \mathrm{mL}$ CpG for 5 days. ELISpot 96-well filtration plates (MSIPS4510; Millipore, Temecula, Calif) were precoated with either $0.5 \mu \mathrm{g}$ of anti-IgG (109-006-088; Novakemi, Handen, Sweden) or $2 \mu \mathrm{g}$ per well of measles antigen and subsequently loaded with $3 \times 10^{5}$ cells per well. Plates were then processed, as previously described, ${ }^{16}$ and analyzed with an ELISpot reader. The frequency of memory B cells was calculated as related to total PBMCs. The ability of memory B cells to differentiate into ASCs in response to BCR stimulation, TLR9 stimulation, or both was evaluated, as previously described. ${ }^{15}$

\section{Detection of ROS in B cells}

Total human PBMCs or purified B cells were resuspended at a concentration of $2.5 \times 10^{5}$ cells per well and incubated for 30 minutes at $37^{\circ} \mathrm{C}$ in the presence or absence of phorbol 12-myristate 13-acetate (PMA; $1 \mu \mathrm{mol} / \mathrm{L}$ ). Cells were further incubated for 45 minutes at $37^{\circ} \mathrm{C}$ in the dark with $0.5 \mu \mathrm{mol} / \mathrm{L} 2^{\prime}, 7^{\prime}$-dichlorodihydrofluorescein diacetate (Invitrogen) and labeled with anti-CD19 (BD). ROS emission was measured with a FACSCanto (BD). Purified B cells were obtained by means of negative selection, according to the manufacturer's protocol (MACS System; Miltenyi Biotec, Bergisch Gladbach, Germany). After isolation, the purity of $\mathrm{CD} 19^{+}$cells was greater than $95 \%$.

\section{Quantification of measles-specific plasma antibodies}

Plasma antibody titers against measles were measured with the Enzygnost Anti-measles Virus/IgG ELISA kit (Dade Behring, Deerfield, Ill), according to the manufacturer's instructions. The protective threshold was set at $0.12 \mathrm{IU} / \mathrm{mL}$ for measles. ${ }^{17}$

\section{gp91 ${ }^{\text {phox }}$ Expression on B cells of CGD carriers}

Total PBMCs of 4 patients, their mothers, and HCs were labeled with antihuman gp91 ${ }^{\text {phox }}$ (Medical and Biological Laboratories, Nagoya, Japan), CD19allophycocyanin and CD14-phycoerythrin (BD) were added, and the cells were incubated for 20 minutes at $4^{\circ} \mathrm{C}$, washed, and analyzed on FACSCanto II (BD).

\section{Statistics}

The Mann-Whitney and Wilcoxon matched-pairs signed-rank tests were used to compare median values between patients and HCs by using GraphPad Prism software (GraphPad Software, La Jolla, Calif).

\section{RESULTS}

\section{Characterization of B-cell subsets in patients with CGD}

Whether the deficit in NADPH oxidase characterizing patients with CGD can alter the development and function of $\mathrm{B}$ cells remains not fully explored. Comparison of patients with CGD with sex- and age-matched HCs revealed significantly lower percentages of switched memory $\mathrm{B}$ cells $\left(\mathrm{CD} 19^{+} \mathrm{CD} 27^{+} \mathrm{IgD}^{-}\right)$in patients with CGD $(P=.041$; Fig $1, B)$. In contrast, numbers of naive B cells $\left(\mathrm{CD} 19^{+} \mathrm{CD} 27^{-} \mathrm{IgD}^{+}\right)$were greater in patients with $\mathrm{CGD}$ compared with those in HCs in terms of percentages $(P=.049$; Fig $1, B)$ and total counts $(P=.022$; Fig $1, D)$. Among mature B-cell subsets, patients with CGD showed differences in percentages of resting memory $\mathrm{B}$ cells $\left(\mathrm{CD} 19^{+} \mathrm{CD} 10^{-} \mathrm{CD} 21^{+} \mathrm{CD} 27^{+}\right)$ when compared with HCs $(P=.0053)$. Other B-cell subsets, such as tissue-like $\left(\mathrm{CD} 19^{+} \mathrm{CD} 10^{-} \mathrm{CD} 21^{-} \mathrm{CD} 27^{-}\right)$, activated memory $\left(\mathrm{CD} 19^{+} \mathrm{CD} 10^{-} \mathrm{CD} 21^{-} \mathrm{CD} 27^{+}\right)$, and immature transitional $\left(\mathrm{CD} 19^{+} \mathrm{CD} 24^{+} \mathrm{CD} 38^{+} \mathrm{CD} 10^{+}\right)$cells, were comparable between the 2 groups (Fig 1, C). In addition, higher frequencies of 
double-negative $\left(\mathrm{CD} 19^{+} \mathrm{CD}^{-} 7^{-} \mathrm{IgD}^{-}\right)$cells were observed among patients with CGD compared with $\mathrm{HCs}$, although a statistical difference was not reached $(P=.081$; Fig $1, B)$.

To rule out whether these observations were related to lymphopenia, we re-evaluated the above data, taking into account absolute white blood cell counts (Table I). Normal white blood cell counts and a nonsignificant increase in total B-cell counts were observed in patients with CGD compared with $\mathrm{HCs}$ (Fig 1,D). Interestingly, although the number of naive B cells was increased among patients with CGD $(P=.022)$, total memory $(P=.0059)$ and resting memory $(P=.043)$ B-cell counts were consistently lower in patients with CGD compared with those in HCs. In conclusion, our data indicate that patients with CGD present a selective paucity in resting memory B-cell counts, together with an accumulation of naive B cells.

\section{B-cell proliferation is impaired on single BCR or TLR9 stimulation among patients with CGD}

To investigate B-cell functional responses in patients with CGD, we next sought to assess the ability of B cells from patients with CGD to proliferate on different in vitro stimulations engaging the BCR or TLR9 pathways. Total PBMCs from patients with CGD and HCs were labeled with carboxyfluorescein succinimidyl ester and cultured for 5 days in the presence of different stimuli, and B-cell proliferation was subsequently analyzed by means of flow cytometry (Fig 2, A). PWM is widely used as a B-cell stimulatory reagent to elicit B-cell expansion with concomitant differentiation of B cells into ASCs. ${ }^{18}$

B cells from patients with CGD showed a significantly lower proliferation after PWM stimulation $(P=.009)$ compared with those from HCs (Fig 2, B). The B-cell mitogenic effect of PWM was recently shown to result from synergistic activity of the pokeweed lectin and microbial TLR2/9 ligands present in the PWM preparations. ${ }^{19}$ To investigate whether reduced B-cell proliferation in patients with CGD after PWM stimulation is related to perturbations in BCR or TLR9 pathways, we conducted single or combined stimulations using anti-Ig for BCR cross-linking and $\mathrm{CpG}$ for TLR9 stimulations. B cells from patients with CGD showed a significantly lower proliferation after single stimulation with either anti-Ig $(P=.019)$ or $\mathrm{CpG}(P=.017)$ compared with HCs.

Conversely, comparable B-cell responses between patients with CGD and HCs were observed when exposed to combinations of $\mathrm{CpG}$ plus anti-Ig or PWM plus anti-Ig (Fig 2, B). To investigate whether there was lower proliferation of $\mathrm{B}$ cells in CGD patients with stimuli singularly directed to BCR or TLR9, we further monitored cell proliferation of memory $\left(\mathrm{CD} 19^{+} \mathrm{CD} 27^{-} \mathrm{IgD}^{-}\right)$ and naive $\left(\mathrm{CD} 19^{+} \mathrm{CD} 27^{-} \mathrm{IgD}^{+} \mathrm{CD} 10^{-}\right) \mathrm{B}$ cells (see Fig E1 in this article's Online Repository at www.jacionline.org). Partial impairments were observed in both memory and naive B-cell proliferation on single stimuli, which were compensated when these stimuli were given together, as shown for total B cells. Collectively, these data suggest that synergistic engagement of BCR and TLR9 signaling pathways might be required to compensate for intrinsic defects in CGD-derived B cells.

\section{ROS after PMA stimulation in B cells of patients with CGD}

Small and localized amounts of ROS have been reported to modulate lymphocyte activation and proliferation. ${ }^{8}$ To investigate whether the above-described alteration in B-cell proliferation from patients with CGD is related to NADPH oxidase activity, we used a flow cytometric assay to specifically measure ROS levels in B cells from patients with CGD and HCs after B-cell activation. Our results show that the modulation of ROS activity, intended as a fold increase of ROS after PMA stimulation, is significantly lower among patients with CGD compared with that seen in HCs $(P=.006$, Fig 3$)$. To exclude that measured ROS in B cells originated through diffusion from bystander cells among total PBMCs, we repeated the above experiments with purified $\mathrm{B}$ cells isolated by means of negative selection. Comparable results were observed between sorted B cells and CD19 ${ }^{+}$B cells gated out of total PBMCs (see Fig E2, A, in this article's Online Repository at www.jacionline.org), thus confirming our observation that B cells from patients with CGD carry intrinsic defects of NAPDH oxidase. Modulation of ROS was analyzed on myelocytic cells among patients with CGD and HCs to analyze the sensitivity of the probe considering the low increase in terms of B-cell ROS formation. Confirming previous evidence, ${ }^{8}$ data showed that the increase in ROS levels is physiologically higher among myelocytoid cells from HCs compared with B lymphocytes, where ROS are found in lower proportions (see Fig E2, B).

\section{Impaired proliferation is associated with lower frequencies of measles-specific ASCs}

Measles-specific antibodies were reported to be maintained through life and to correlate with the level of total memory B cells in the periphery. ${ }^{20}$ For this reason, this antigen is used as a model to dissect long-term memory maintenance and analyzed in this study. In vivo exposure to cognate antigens (in the form of reinfection or booster vaccination) results in the activation of memory B cells and their subsequent proliferation and differentiation into antibody-secreting daughter cells. $^{21,22}$ To assess whether the impaired B-cell proliferation could affect the capacity of memory B cells to differentiate into ASCs, we measured the in vitro differentiation of total PBMCs after stimulation with PWM and $\mathrm{CpG}$ alone or in combination (Fig 4, A).

Results showed that measles-specific ASC frequencies are lower in patients with CGD compared with those seen in HCs. These data were not affected by differences in total IgG-secreting cells between patients with CGD and HCs. Moreover, this result was confirmed on single stimulation (PWM: $P=.033$ and $\mathrm{CpG}$ : $P=.018)$, whereas combined stimulation $(\mathrm{PWM}+\mathrm{CpG})$ only partially recovered specific memory $\mathrm{B}$ cells in these patients (Fig 4, B). Overall, these data confirm the results of the proliferation experiments, suggesting that B cells from patients with CGD need simultaneous triggering of BCR and TLR9 to differentiate into ASCs.

Although total $\mathrm{IgG}$ was not different between patients with CGD and HCs, revealing a good control of the inflammatory phase of the disease, patients with CGD had lower frequencies of serum antibodies against measles $(P=.0234$; Fig $4, C)$. In addition, 4 of 10 patients had antibody levels of less than protective levels (Fig 4,C), according to standard correlates of seroprotection. ${ }^{23}$ Further analyses demonstrated that among patients with CGD, there is an age-related waning of measles serologic immunity $(r=-0.7, P=.022$; Fig $4, D)$ 
TABLE I. Participants' profiles at baseline

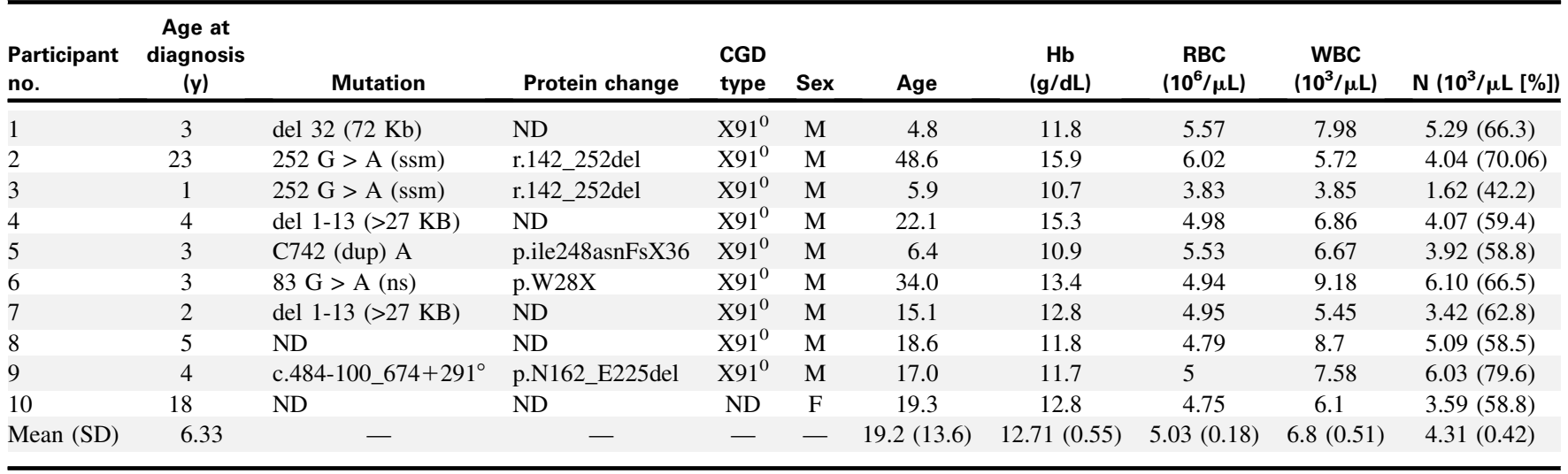

AZA, Azathioprine; $C R P$, C-reactive protein; del, deletion; dup, duplication; $E$, eosinophils; $E S R$, erythrocyte sedimentation rate; $F$, female; $H b$, hemoglobin; $I T C Z$, itraconazole $L$, lymphocytes; $M$, male; $N$, neutrophils; $N D$, not determined; $n s$, nonsense mutation; $P L T$, platelets; $R B C$, red blood cells; ssm, splice site mutation; $T M P$-SMX, trimethoprim/ sulfamethoxazole; $W B C$, white blood cell count.

A
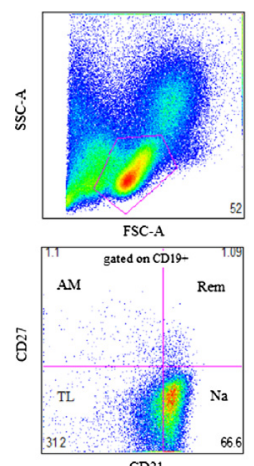

CD21
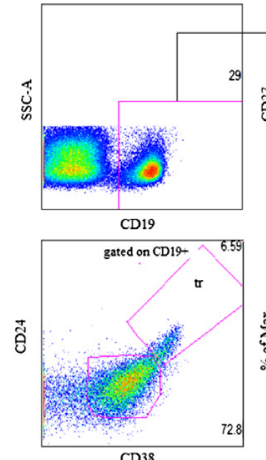
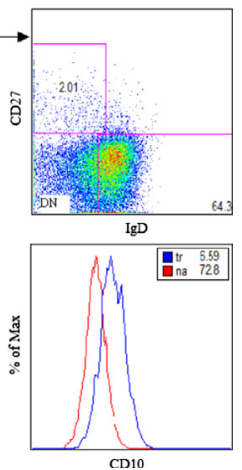

C

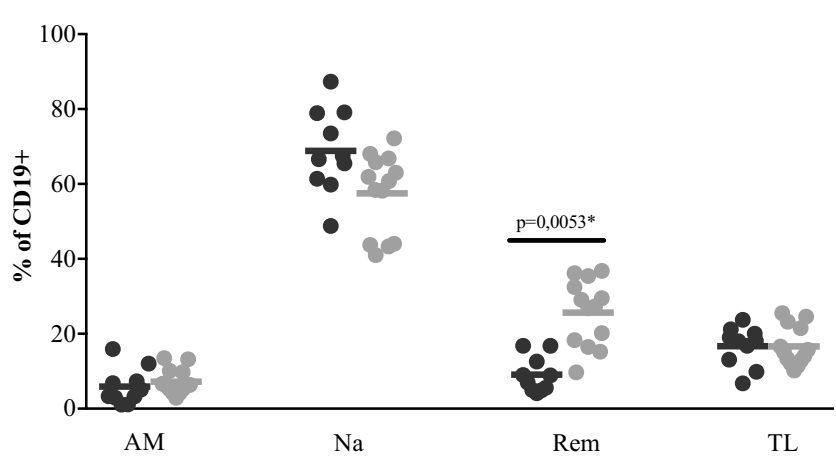

B

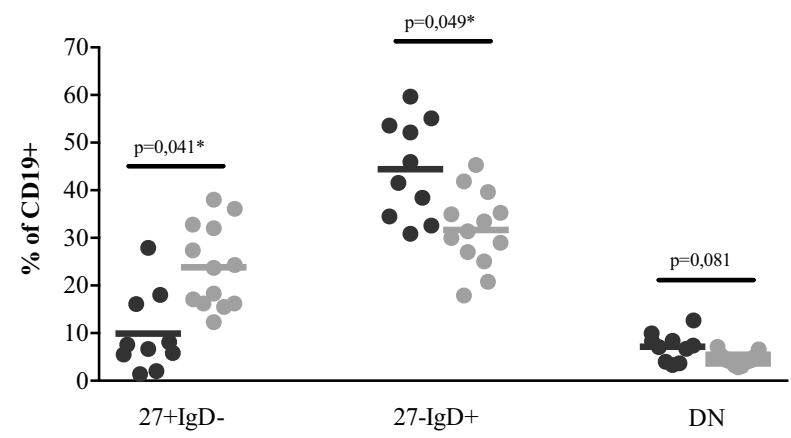

CGD

HC

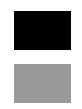

D

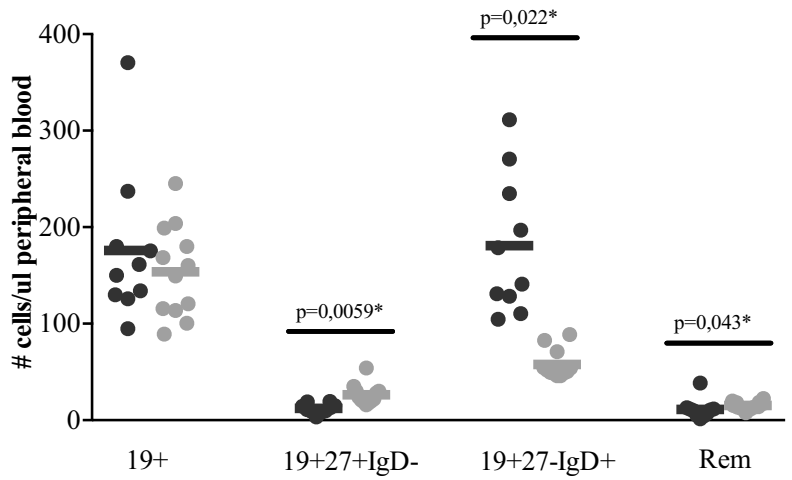

FIG 1. The B-cell phenotype of patients with CGD is characterized by lower memory and higher naive cell counts. Representative gates (A) and comparisons of B-cell percentages (B and C) and absolute counts (D) are shown. Horizontal bars represent medians. $P$ values were determined with the nonparametric MannWhitney test. $\mathrm{CD} 19^{+}$cells established the B-cell population, and expression of IgD, CD27, CD21, CD24, $\mathrm{CD} 38$, and $\mathrm{CD} 10$ was used to define total naive $\left(\mathrm{CD} 27^{-} \lg { }^{+}\right)$, total memory $\left(\mathrm{CD} 27^{+} \lg \mathrm{gD}^{-}\right)$, double-negative $\left(D N ; C^{-} 27^{-} \lg D^{-}\right)$, resting memory $(\operatorname{Rem})$, tissue-like $(T L)$, activated memory $(A M)$, naive $(\mathrm{Na})$, and immature transitional (Tr) cells. FSC, Forward scatter; SSC, side scatter. 


\begin{tabular}{|c|c|c|c|c|c|c|c|c|c|}
\hline$E\left(10^{3} / \mu L[\%]\right)$ & $\mathrm{L}\left(10^{3} / \mu \mathrm{L}[\%]\right)$ & $\operatorname{PLT}\left(10^{3} / \mu \mathrm{L}\right)$ & $\begin{array}{l}\text { Ferritin } \\
\text { (ng/mL) }\end{array}$ & $\begin{array}{c}\lg A \\
(\mathrm{mg} / \mathrm{dL})\end{array}$ & $\begin{array}{c}\lg G \\
(\mathrm{mg} / \mathrm{dL})\end{array}$ & $\begin{array}{c}\operatorname{lgM} \\
(\mathrm{mg} / \mathrm{dL})\end{array}$ & $\begin{array}{c}\text { ESR } \\
(\mathrm{mm})\end{array}$ & $\begin{array}{c}\text { CRP } \\
(\mathrm{mg} / \mathrm{dL})\end{array}$ & Treatment \\
\hline $0.09(1.1)$ & $1.49(18.7)$ & 475 & 49 & 80 & 745 & 117 & 10.00 & 4.58 & TMP-SMX, ITCZ \\
\hline $0.14(2.5)$ & $1.24(21.6)$ & 269 & 140 & 362 & 1275 & 50 & 11 & 0.88 & AZA, TMP-SMX, FLZ \\
\hline $0.13(3.5)$ & $1.82(47.3)$ & 407 & 36 & 109 & 665 & 53 & 7 & 4.76 & TMP-SMX, ITCZ \\
\hline $0.27(3.9)$ & $1.99(29.0)$ & 250 & 54 & 239 & 1373 & 85 & 12 & 0.32 & TMP-SMX, ITCZ \\
\hline $0.7(0.05)$ & $2.05(30.8)$ & 426 & 26 & 128 & 1389 & 109 & 9 & 0.64 & TMP-SMX, ITCZ \\
\hline $0.8(0.07)$ & $2.31(25.2)$ & 228 & 39 & 606 & 1497 & 157 & 14 & 2.03 & TMP-SMX, ITCZ \\
\hline $2.2(1.12)$ & $1.51(27.7)$ & 304 & 45 & $<5$ & 1314 & 61 & 4 & 0.45 & TMP-SMX, ITCZ \\
\hline $0.17(2.0)$ & $2.46(28.3)$ & 291 & 13 & 162 & 2079 & 101 & 5 & 2.37 & TMP-SMX, ITCZ \\
\hline $0.32(4.2)$ & $0.77(10.1)$ & 421 & 106 & 192 & 1612 & 108 & 17 & 3.35 & TMP-SMX, ITCZ \\
\hline $0.29(4.7)$ & $1.88(30.9)$ & 293 & 27 & 191 & 1274 & 206 & 6 & 0.05 & TMP-SMX, ITCZ \\
\hline $0.51(0.20)$ & $1.75(0.50)$ & $336(27.51)$ & $46.9(13.67)$ & $207.4(53.7)$ & $1322(127.5)$ & $104.7(15.33)$ & $9.5(1.31)$ & $1.94(0.56)$ & - \\
\hline
\end{tabular}

A

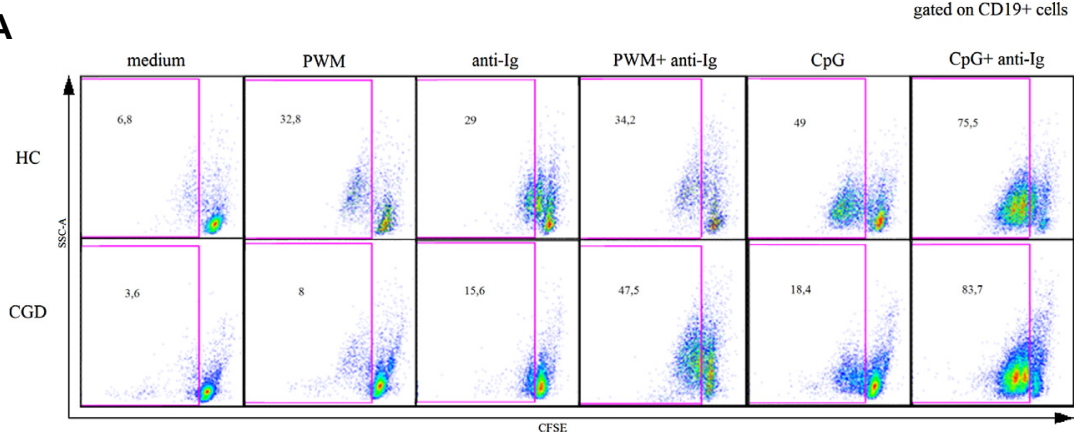

B

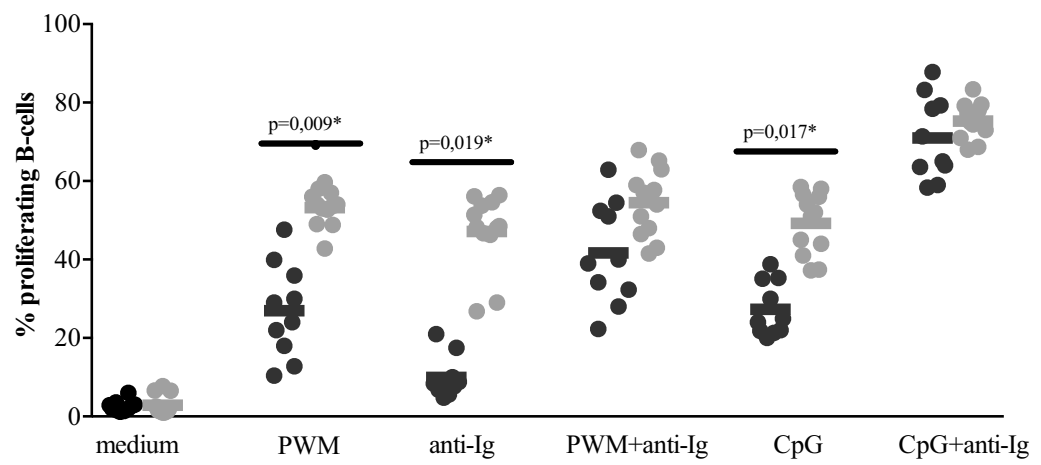

CGD

HC

FIG 2. B-cell proliferation of patients with CGD is reduced if a single stimulus directed to BCR or TLR9 is given. Representative gate of carboxyfluorescein succinimidyl ester (CFSE)-diluted B cells (A) and comparisons of proliferating B-cell percentages between patients with CGD $(n=10)$ and HCs ( $n=13 ; B)$ are shown in the scatter dot plots. Horizontal bars, Medians. Statistics have been defined with the nonparametric Mann-Whitney test, and only significant $P$ values $(P<.05)$ have been reported in the figure. SSC, Side scatter.

not found in HCs (Fig 4, E). All patients with CGD who presented with a lower response after in vitro stimulation for ELISpot assay and serologically unprotected to measles presented common phenotypic characteristics compared with other patients with CGD (Fig 5). In fact, ELISpot assay nonresponders presented lower levels of total $(P=.022)$ and resting memory $(P=.0356) \mathrm{B}$ cells compared with ELIspot assay responders. ELISpot assay responders showed lower naive B-cell counts $(P=.0044)$ compared with ELISpot assay nonresponders with CGD (Fig 5). No correlation with age was found between responders and nonresponders. Together, these results identify a relation between impaired maintenance of memory response and phenotype in patients with CGD. 
A

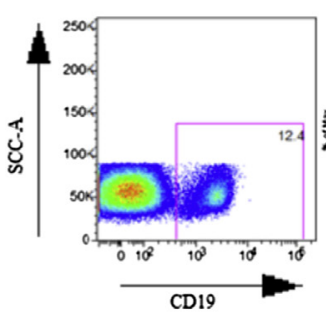

gated on CD19+

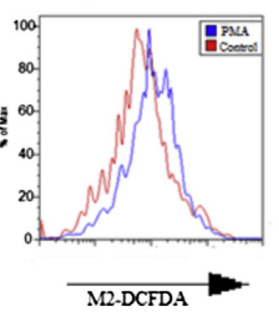

B

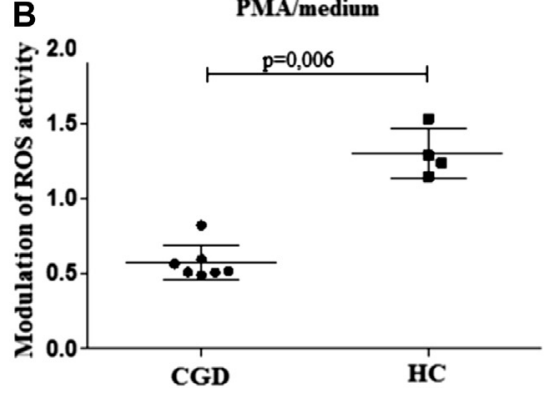

FIG 3. ROS activity is hampered in B cells affected by CGD. Representative gate (A) and comparisons (B) between patients with CGD and HCs in terms of modulation of ROS with and without PMA stimulation on gated $\mathrm{CD}_{19^{+}}$cells are shown. Modulation of ROS is defined as the ratio of the geometric mean of M2-2',7'-dichlorodihydrofluorescein diacetate (DCFDA) before and after PMA stimulation. Means and SEMs are shown in the graph. Statistics have been defined with the nonparametric Mann-Whitney test. SSC, Side scatter.

A

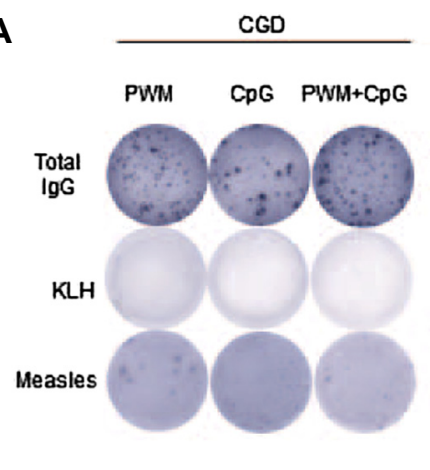

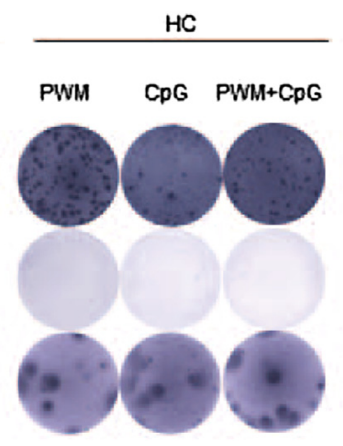

B

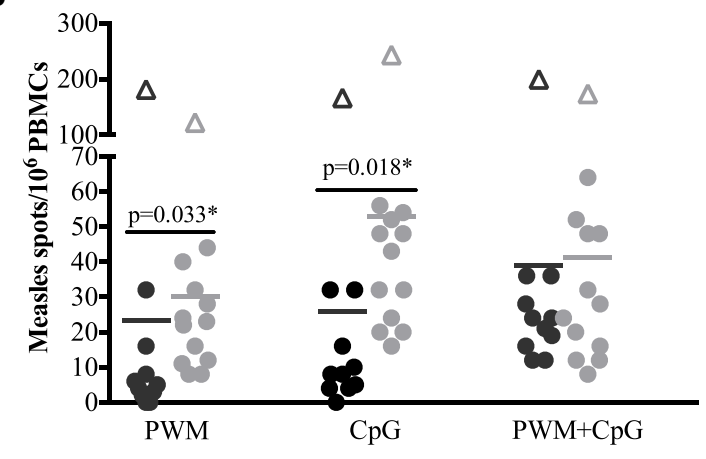

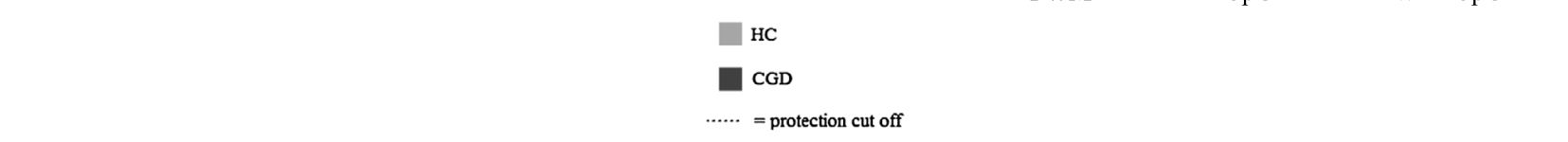
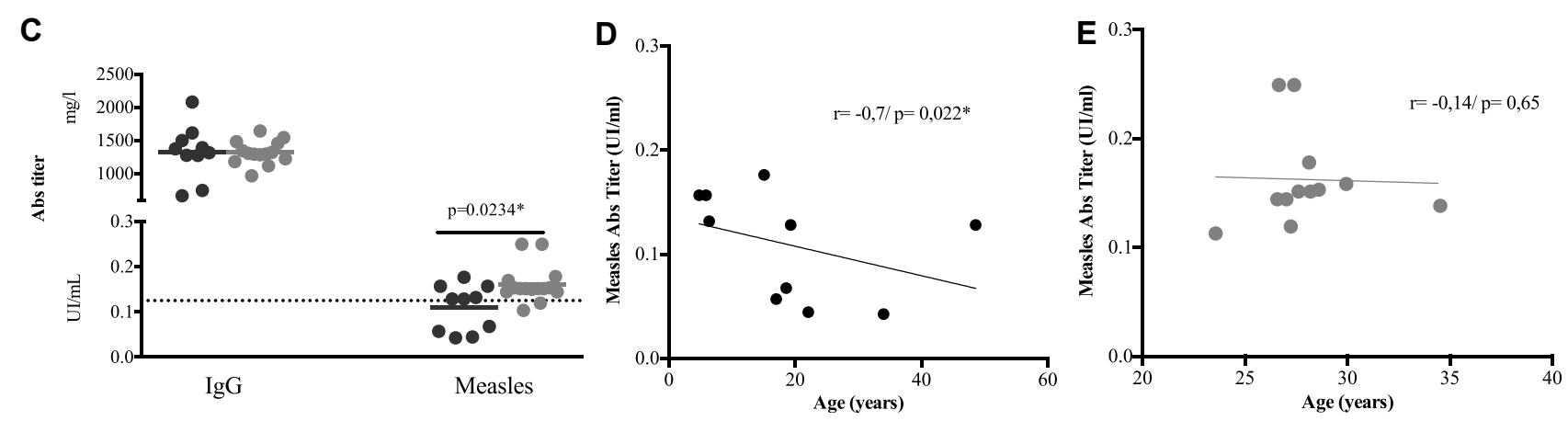

FIG 4. In vitro and in vivo responses to measles in patients with CGD are lower compared with those seen in HCs. Representative ELISpot assay analysis (A) and comparisons (B) between patients with CGD and HCs are shown in the graph. Open triangles, Average of the IgG spots; horizontal bars, medians. Specific antibodies for measles and total $\lg$ (C) and correlation (Spearman test) with age in patients with CGD (D) and HCs (E) are shown. $K L H$, Keyhole limpet hemocyanin.

\section{B-cell defects in a competitive setting: Phenotype and proliferation among CGD carriers}

To investigate whether B-cell defects could be found in a competitive setting, we investigated CGD carriers. We observed that mothers with CGD express different levels of gp91 ${ }^{\text {phox }}$-positive B cells (Fig 6, B) and $\mathrm{CD} 14^{+}$cells (data not shown).
We further show a partial B-cell impairment among CGD carriers compared with that seen in HCs. In fact, higher levels of total naive and lower total memory levels are found among CGD carriers. In addition, resting memory cell counts are significantly lower compared with those in HCs $(P=.028$; Fig $6, D)$. Similar data are shown in the proliferation experiments, where CGD carriers show a lower proliferation rate on single 


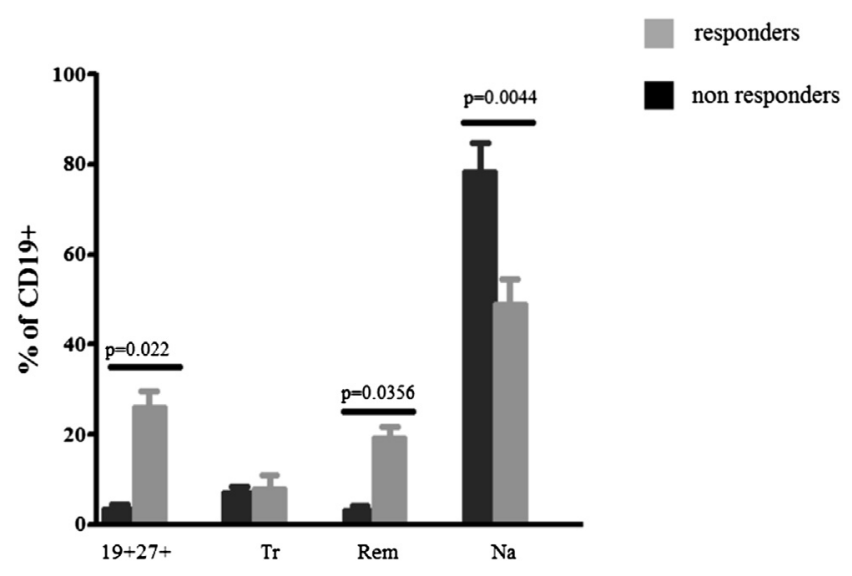

FIG 5. Patients with CGD not producing measles-specific ASCs have lower memory and higher naive B cells. Among patients with CGD, 2 groups were created according to numbers of ASCs for measles. Responders and nonresponders have been selected according to the number of $A S C s / 10^{6}$ cells greater than or less than the mean plus SD. The nonparametric Mann-Whitney test was used to analyze data. Box plots show means and SEMs. Na, Naive cells; Rem, resting memory cells; Tr, immature transitional cells.

stimuli compared with that seen in HCs, although not significantly so (Fig 6, E).

Interestingly, CGD carriers with lower numbers of gp91 ${ }^{\text {phox }}$-positive B cells presented lower memory and higher naive $B$ cells in parallel to lower proliferation rates on single stimuli. In line with this, mothers with CGD with higher selective advantage seem to compensate these defects.

\section{DISCUSSION}

In the present study we focused on the analysis of B-cell phenotype and function in patients affected by CGD, with the aim of assessing whether the deficit in NADPH oxidase characterizing these patients could directly affect B-cell functions in a setting free of immunosuppressive drugs. This might be particularly important because inhomogeneous effects of immunosuppressive drugs on different total B-cell subtypes and antigen-specific memory B cells can occur. First, we confirmed that patients affected by CGD present lower frequencies of memory B cells ${ }^{9,10}$ and higher frequencies of naive B cells. In addition, we show that both naive and memory B cells from these patients present a lower ability to proliferate and differentiate into ASCs on in vitro stimulations singularly directed to TLR9 or BCR. Such impairment is related to a suboptimal capacity of these patients to maintain long-term memory responses, as revealed by the dissection of measles-specific antibody responses.

These data are in contrast to a previous report ${ }^{24}$ in mice with gp91 ${ }^{\text {phox }}$ deficiency, suggesting that ROS production is inversely related to BCR proliferation. On the other hand, our results support previous observations that ROS activity can enhance protein tyrosine kinase by inhibiting protein tyrosine phosphatase activity after BCR stimulation. ${ }^{25-27}$

Among patients with CGD, the defective proliferation and differentiation into ASCs in response to stimuli that are solely directed to TLR9 (CpG) or BCR (anti-Ig) is compensated if these stimuli are given together. Accordingly, restoration of the proliferative ability on combined stimulation with both BCR and TLR could be due to activation of naive B cells, in which the synergic activation of both pathways is required. ${ }^{28,29}$ In view of this, it is possible that dysfunctional NADPH oxidase activity on naive $\mathrm{B}$ cells in vivo might directly affect the capability of these cells to differentiate into memory cells. In fact, patients with CGD have been reported to have lower total memory B-cell counts $\left(\mathrm{CD} 19^{+} \mathrm{CD} 27^{+}\right)$and resting memory B-cell counts $\left(\mathrm{CD} 19^{+} \mathrm{CD} 10^{-} \mathrm{CD} 21^{+} \mathrm{CD} 27^{+}\right) .{ }^{10}$ In the present study we confirmed these findings.

Further investigations were performed on measles-specific immunity to study the effects of CGD on the maintenance of long-term serologic memory. To date, measles-specific antibodies are known to be long term and directly correlated with levels of total memory B cells in the periphery. ${ }^{20}$ Results pointed out significantly lower serum antibody levels against measles and impaired differentiation of measles-specific memory B cells to ASCs among patients with CGD compared with HCs. Interestingly, an age-related reduction in measles-specific antibody levels was found among patients with CGD. This further points out the impaired recall/maintenance of antigen-specific memory B cells in patients with CGD, which, in the case of measles, should confer serologic memory for the entire lifespan in healthy subjects. ${ }^{20}$ A similar scenario occurs in other diseases characterized by chronic immune activation, ${ }^{16,30,31}$ in which the capacity to confer durable protection after vaccination is reduced and related to low memory B-cell frequencies. ${ }^{32,33}$

Thus a possible explanation for the loss of long-term memory in patients with CGD can be an ineffective polyclonal activation of memory B cells, which usually maintain serologic memory. $^{28,34,35}$ However, we also found numbers of CD27/IgD double-negative B cells, which were previously described as increased in elderly healthy subjects, ${ }^{36}$ HIV-infected children, and patients undergoing kidney transplantation, ${ }^{37}$ to be higher among patients with CGD compared with those seen in HCs. This might support the hypothesis that B cells from patients with CGD could also be unresponsive to stimuli because of premature aging. In HIV-infected children and patients undergoing kidney transplantation, this is due to B-cell chronic activation. ${ }^{37}$ This suggest that B cells from patients with CGD might be subjected to a similar chronic activation status as a result of the inflammatory milieu.

To further investigate the B-cell defect in the context of a competitive setting, we studied B cells from mothers with CGD. CGD carriers showed a partial impairment in terms of phenotype and proliferation on single stimuli. Interestingly, our data show that these functional defects seem inversely related to the selective advantage in B cells. These results fit with recent data showing that female carriers, who are usually considered unaffected, display clinical manifestations that often underlie an autoimmune pathogenesis. $^{38}$

On the other hand, our investigation has focused on understanding whether the congenital defective production of ROS could impair B-cell lymphocyte activation and proliferation after specific stimuli. In patients with CGD, this altered production of ROS renders the patient's phagocytes unable to kill ingested microorganisms, resulting in increased susceptibility to bacterial and fungal infections. However, several pieces of evidence indicate the importance of ROS, although at different concentrations, to act as secondary messengers in lymphocyte activation. ${ }^{8,39,40}$ Furthermore, it has been shown 
A

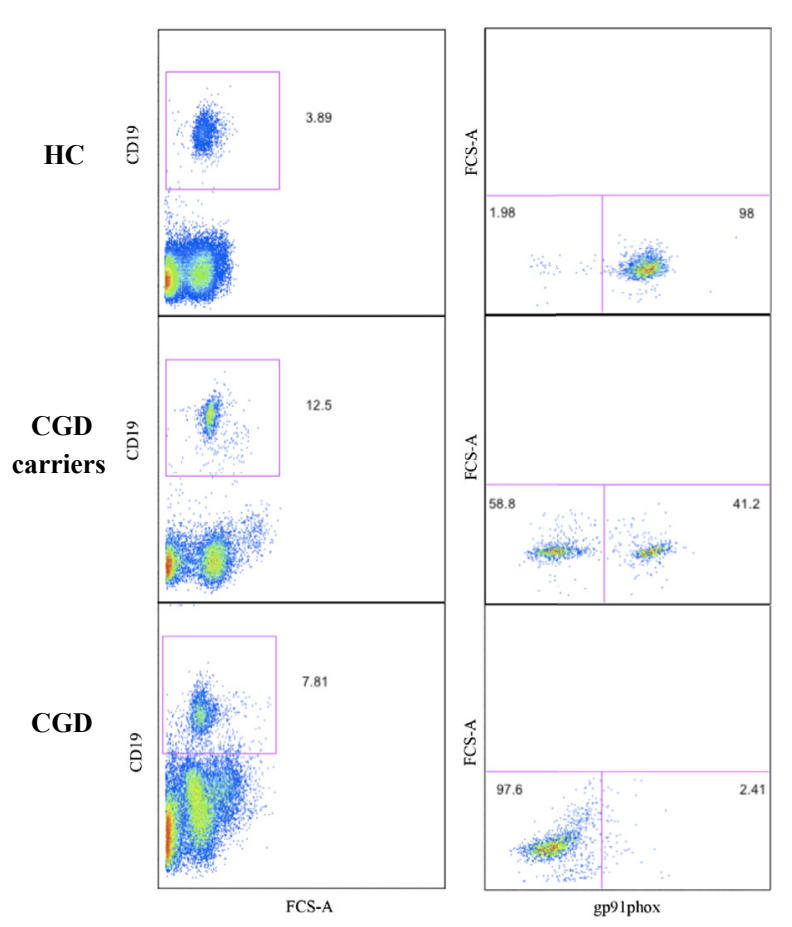

B

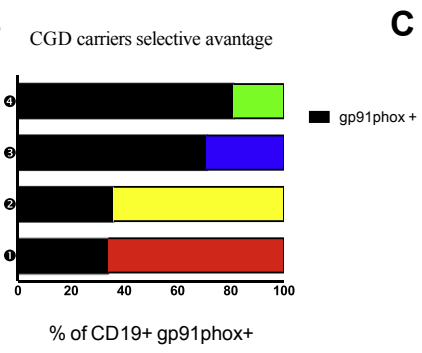

D
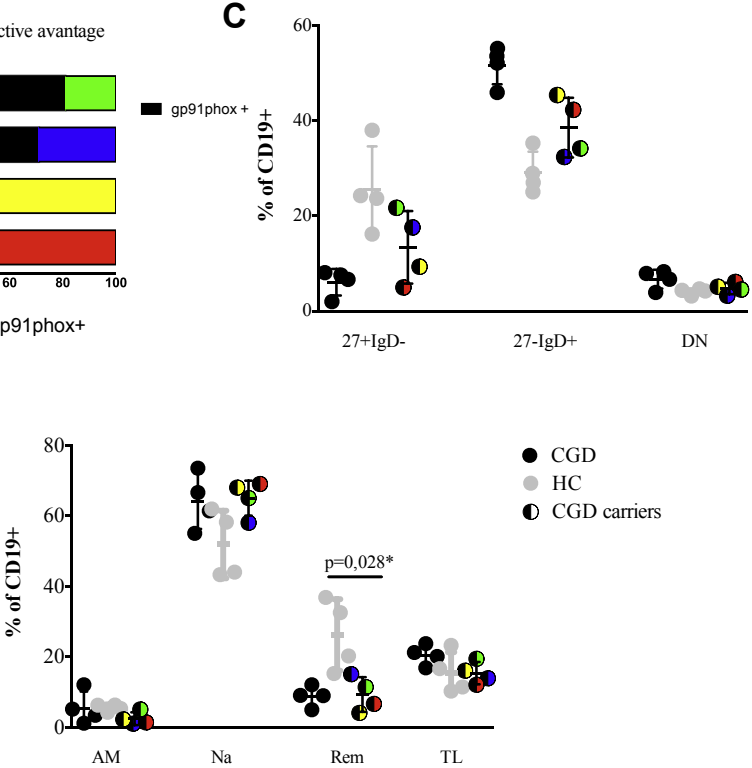

E

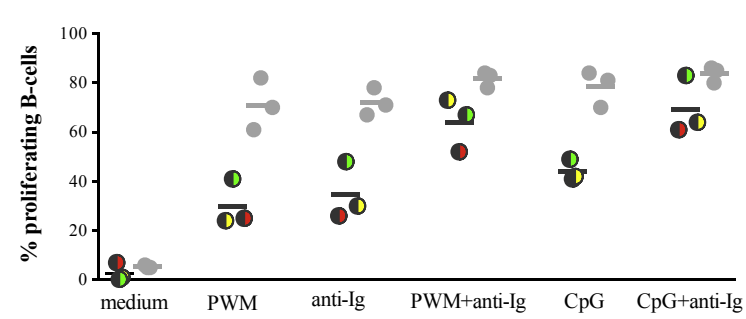

FIG 6. Selective advantage of CGD carriers relates to B-cell defects. Representative gate (A) and contingency graph (B) of gp91 ${ }^{\text {phox }}$-positive B cells in mothers with CGD are shown. Comparisons of B-cell phenotype $(C$ and $\mathbf{D})$ and proliferation (E) between HCs, patients with CGD, and CGD carriers are also shown. Different dot colors refer to the different CGD carriers according to selective advantage shown in Fig $6, B$. The MannWhitney test was used to analyze data. Means and SDs are shown in the graphs. AM, Activated memory cells; $N a$, naive cells; Rem, resting memory cells; $T L$, tissue-like cells.

that $\mathrm{H}_{2} \mathrm{O}_{2}$ plays a critical role in the activation of the antigen receptor on lymphocytes because this signaling cascade requires not only activation of kinases but, more importantly, inhibition of phosphatases that are critically regulated by $\mathrm{H}_{2} \mathrm{O}_{2} \cdot{ }^{8,25}$ This evidence has been confirmed on $\mathrm{B}$ cells from mutant mice for HVCN1 or Ncf1, ${ }^{11,12}$ thus emulating the alteration of NADPH oxidase activity of patients with CGD. Such an experimental model showed altered B-cell function and proliferative ability. Our results show that ROS production in B cells after PMA stimulation is lower among patients with CGD compared with that seen in HCs. Thus we present evidence for an intrinsic decrease in total NADPH activity in B cells; a caveat in our findings is the limitation of available methods to directly link ROS production to B-cell signaling rather than to proliferation. ${ }^{11,12}$

ROS production in B cells is also involved in other cell functions, including apoptosis, which in turn prevent the uncontrolled proliferation of these cells. In line with this, a higher degree of susceptibility to malignancy and B-cell lymphomas has been reported in patients with CGD. ${ }^{41}$ Although our data primarily show that patients with CGD present an alteration in B-cell proliferation despite a stable healthy condition, further studies are needed to clarify the link between NADPH oxidase defects, impaired proliferation, and tumor genesis.
In conclusion, we report that B cells from patients with CGD show an altered proliferation and differentiation into specific ASCs on single stimuli in parallel to a reduced capacity to maintain long-term serologic memory. In addition, patients with CGD with lower values of specific ASCs showed common B-cell phenotypic characteristics, such as low memory and high naive B-cell percentages. Hence this evidence could guide clinicians in performing more specific B-cell assays in patients presenting with such a B-cell phenotype and in evaluating these patients as eligible for a personalized immunization schedule.

It is still unclear why specific stimuli, singularly directed to the BCR or TLR9 in patients with CGD, elicit lower proliferation compared with HCs and why partial recovery is seen on combined stimulation with TLR9 and BCR. Future efforts are needed to find out whether this is due to a higher percentage of naive B cells in patients with CGD compared with HCs or whether this is due to a direct role of ROS production deficiency because of the NADPH oxidase defect, which in turn affect the specific single stimuli of BCR and TLR9 expression. A deeper knowledge of how NADPH oxidase affects B-cell function could shed light on the mechanisms underlying long-term memory maintenance. This evidence might play a key role in the development of new vaccination adjuvants and the design of new survey models and revaccination programs to maintain a 
long-term protective memory in patients affected by immune deficiencies.

We thank all patients and guardians who decided to participate in the study. We thank Emma C. Manno for assistance with sample collection; Stephan Meinke, Stefano Rinaldi, and Simona Cascioli for their valuable technical support; and Miss Jennifer Faudella for her secretarial work

\section{Key messages}

- Patients with CGD present an altered cellular distribution in the B-cell compartment.

- Combined stimuli to BCR and TLR9 in patients affected by CGD are required to elicit an efficient B-cell proliferation and ASC differentiation.

- There are lower memory and higher naive B-cell counts related to impaired long-term memory in patients with CGD.

\section{REFERENCES}

1. Lambeth JD. NOX enzymes and the biology of reactive oxygen. Nat Rev Immunol 2004:4:181-9.

2. Winkelstein JA, Marino MC, Johnston RB Jr, Boyle J, Curnutte J, Gallin JI, et al Chronic granulomatous disease. Report on a national registry of 368 patients. Medicine (Baltimore) 2000;79:155-69.

3. Segal BH, Leto TL, Gallin JI, Malech HL, Holland SM. Genetic, biochemical, and clinical features of chronic granulomatous disease. Medicine (Baltimore) 2000;79: 170-200

4. Dinauer MC, Orkin SH. Chronic granulomatous disease. Annu Rev Med 1992;43: $117-24$

5. Roos D. The genetic basis of chronic granulomatous disease. Immunol Rev 1994; 138:121-57

6. Kuhns DB, Alvord WG, Heller T, Feld JJ, Pike KM, Marciano BE, et al. Residual NADPH oxidase and survival in chronic granulomatous disease. N Engl J Med 2010;363:2600-10.

7. Ha YJ, Lee JR. Role of TNF receptor-associated factor 3 in the CD40 signaling by production of reactive oxygen species through association with p40phox, a cytosolic subunit of nicotinamide adenine dinucleotide phosphate oxidase. J Immunol 2004;172:231-9.

8. Reth M. Hydrogen peroxide as second messenger in lymphocyte activation. Nat Immunol 2002:3:1129-34.

9. Bleesing JJ, Souto-Carneiro MM, Savage WJ, Brown MR, Martinez C, Yavuz S, et al. Patients with chronic granulomatous disease have a reduced peripheral blood memory B cell compartment. J Immunol 2006;176:7096-103.

10. Moir S, De Ravin SS, Santich BH, Kim JY, Posada JG, Ho J, et al. Humans with chronic granulomatous disease maintain humoral immunologic memory despite low frequencies of circulating memory B cells. Blood 2012;120:4850-8.

11. Capasso M, Bhamrah MK, Henley T, Boyd RS, Langlais C, Cain K, et al. HVCN1 modulates BCR signal strength via regulation of BCR-dependent generation of reactive oxygen species. Nat Immunol 2010;11:265-72.

12. Wheeler ML, Defranco AL. Prolonged production of reactive oxygen species in response to B cell receptor stimulation promotes B cell activation and proliferation. J Immunol 2012;189:4405-16.

13. Volkman DJ, Buescher ES, Gallin JI, Fauci AS. B cell lines as models for inherited phagocytic diseases: abnormal superoxide generation in chronic granulomatous disease and giant granules in Chediak-Higashi syndrome. J Immunol 1984;133: 3006-9.

14. Di Matteo G, Giordani L, Finocchi A, Ventura A, Chiriaco M, Blancato J, et al Molecular characterization of a large cohort of patients with chronic granulomatous disease and identification of novel CYBB mutations: an Italian multicenter study. Mol Immunol 2009;46:1935-41

15. Douagi I, Gujer C, Sundling C, Adams WC, Smed-Sorensen A, Seder RA, et al. Human B cell responses to TLR ligands are differentially modulated by myeloid and plasmacytoid dendritic cells. J Immunol 2009;182:1991-2001.

16. Pensieroso S, Cagigi A, Palma P, Nilsson A, Capponi C, Freda E, et al. Timing of HAART defines the integrity of memory B cells and the longevity of humora responses in HIV-1 vertically-infected children. Proc Natl Acad Sci U S A 2009; 106:7939-44

17. Chen RT, Markowitz LE, Albrecht P, Stewart JA, Mofenson LM, Preblud SR, et al. Measles antibody: reevaluation of protective titers. J Infect Dis 1990 162:1036-42.

18. Crotty S, Aubert RD, Glidewell J, Ahmed R. Tracking human antigen-specific memory B cells: a sensitive and generalized ELISPOT system. J Immunol Methods 2004;286:111-22.

19. Bekeredjian-Ding I, Foermer S, Kirschning CJ, Parcina M, Heeg K. Poke weed mitogen requires Toll-like receptor ligands for proliferative activity in human and murine B lymphocytes. PLoS One 2012;7:e29806.

20. Amanna IJ, Carlson NE, Slifka MK. Duration of humoral immunity to common viral and vaccine antigens. N Engl J Med 2007;357:1903-15.

21. Amanna IJ, Slifka MK. Mechanisms that determine plasma cell lifespan and the duration of humoral immunity. Immunol Rev 2010;236:125-38.

22. Pierce SK, Liu W. The tipping points in the initiation of B cell signalling: how small changes make big differences. Nat Rev Immunol 2010;10:767-77.

23. Cagigi A, Cotugno N, Giaquinto C, Nicolosi L, Bernardi S, Rossi P, et al. Immune reconstitution and vaccination outcome in HIV-1 infected children: present knowledge and future directions. Hum Vaccin Immunother 2012;8:1784-94.

24. Richards SM, Clark EA. BCR-induced superoxide negatively regulates B-cell proliferation and T-cell-independent type 2 Ab responses. Eur J Immunol 2009;39: 3395-403.

25. Singh DK, Kumar D, Siddiqui Z, Basu SK, Kumar V, Rao KV. The strength of receptor signaling is centrally controlled through a cooperative loop between $\mathrm{Ca} 2+$ and an oxidant signal. Cell 2005;121:281-93.

26. Paclet MH, Coleman AW, Burritt J, Morel F. NADPH oxidase of Epstein-Barrvirus immortalized B lymphocytes. Effect of cytochrome b(558) glycosylation. Eur J Biochem 2001;268:5197-208.

27. Morel F, Cohen Tanugi Cholley L, Brandolin G, Dianoux AC, Martel C, Champelovier $\mathrm{P}$, et al. The $\mathrm{O} 2$ - generating oxidase of B lymphocytes: Epstein-Bar virus-immortalized B lymphocytes as a tool for the identification of defective components of the oxidase in chronic granulomatous disease. Biochim Biophys Acta $1993 ; 1182: 101-9$

28. Bernasconi NL, Onai N, Lanzavecchia A. A role for Toll-like receptors in acquired immunity: up-regulation of TLR9 by BCR triggering in naive B cells and constitutive expression in memory B cells. Blood 2003;101:4500-4.

29. Peng SL. Signaling in B cells via Toll-like receptors. Curr Opin Immunol 2005; 17 : 230-6

30. Cotugno N, Douagi I, Rossi P, Palma P. Suboptimal immune reconstitution in vertically HIV infected children: a view on how HIV replication and timing of HAART initiation can impact on T and B-cell compartment. Clin Dev Immunol 2012;2012: 805151.

31. Rieber N, Hector A, Kuijpers T, Roos D, Hartl D. Current concepts of hyperinflammation in chronic granulomatous disease. Clin Dev Immunol 2012;2012:252460.

32. Cagigi A, Rinaldi S, Cotugno N, Manno EC, Santilli V, Mora N, et al. Early highlyactive antiretroviral therapy enhances b-cell longevity: a 5 year follow-up. Pediat Infect Dis J 2014;33:e126-31

33. Abzug MJ, Song LY, Levin MJ, Nachman SA, Borkowsky W, Pelton SI, et al. Antibody persistence and immunologic memory after sequential pneumococcal conjugate and polysaccharide vaccination in HIV-infected children on highly active antiretroviral therapy. Vaccine 2013;31:4782-90.

34. Bernasconi NL, Traggiai E, Lanzavecchia A. Maintenance of serological memory by polyclonal activation of human memory B cells. Science 2002;298:2199-202.

35. Traggiai E, Puzone R, Lanzavecchia A. Antigen dependent and independent mechanisms that sustain serum antibody levels. Vaccine 2003;21(suppl 2):S35-7.

36. Colonna-Romano G, Bulati M, Aquino A, Pellicano M, Vitello S, Lio D, et al. A double-negative (IgD-CD27-) B cell population is increased in the peripheral blood of elderly people. Mech Ageing Dev 2009;130:681-90.

37. Cagigi A, Rinaldi S, Santilli V, Mora N, Manno EC, Cotugno N, et al. Premature aging of the immune system relates with increased anti-lymphocyte antibodie (ALA) after an immunization in HIV-1 infected and kidney transplanted patients. Clin Exp Immunol 2013;174:274-80.

38. Battersby AC, Cale AM, Goldblatt D, Gennery AR Clinical manifestations of disease in X-linked carriers of chronic granulomatous disease. J Clin Immuno 2013;33:1276-84

39. Segal AW, Shatwell KP. The NADPH oxidase of phagocytic leukocytes. Ann N Y Acad Sci 1997;832:215-22

40. Babior BM, Lambeth JD, Nauseef W. The neutrophil NADPH oxidase. Arch Biochem Biophys 2002;397:342-4.

41. Tran H, Nourse J, Hall S, Green M, Griffiths L, Gandhi MK. Immunodeficiencyassociated lymphomas. Blood Rev 2008;22:261-81. 
A

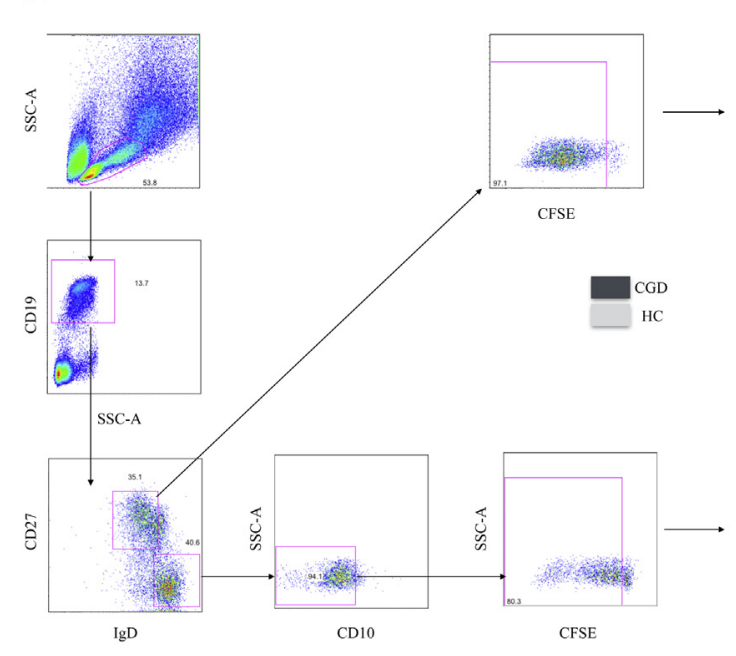

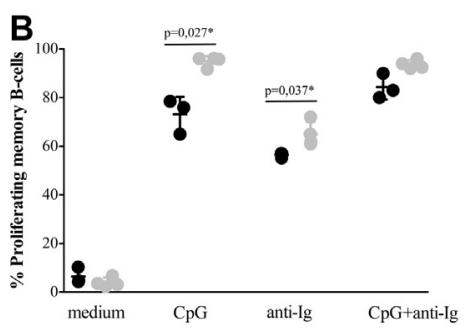

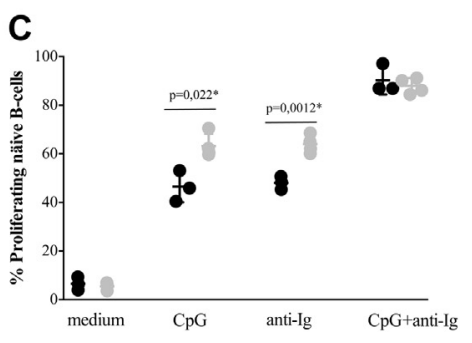

FIG E1. Proliferation of memory and naive B cells. Representative gates (A) and graphs of gated memory (B) and naive (C) B cells are shown. The Mann-Whitney test was used to analyze data. Means and SDs are shown in the graphs. CFSE, Carboxyfluorescein isothiocyanate; SSC, side scatter. 
A

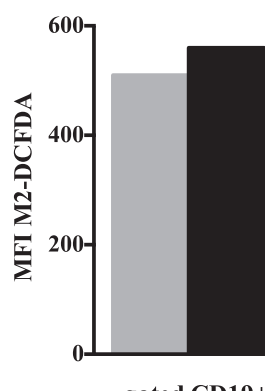

gated CD19 medium
PMA

B

PMA / Medium

FIG E2. ROS production in gated and sorted B cells and myelocytic cells. A, Median fluorescence intensity of gated and sorted $B$ cells are shown in unstimulated cells and after PMA stimuli. B, Modulation of ROS in myelocytic cells and $B$ cells of patients with CGD and HCs. DCFDA, 2',7'-Dichlorodihydrofluorescein diacetate. 